5. Bai, Y., et al., Analysis of Urinary Pathogen Cultures and Drug Sensitivity in Patients with Urinary Stones for Five Consecutive Years in Xiangya Hospital, China. Infection and drug resistance, 2020. 13: p. 1357-1363.
6. Flores-Mireles, A.L., et al., Urinary tract infections: epidemiology, mechanisms of infection and treatment options. Nature reviews. Microbiology, 2015. 13(5): p. 269-284.

\title{
ĐÁNH GIÁ Độ PHÙ HỢP GIỮA KẾT QUẢ MÔ BÊNNH HỌC VÀ ĐĂC ĐIỂM NộI SOI TRONG CHẨN ĐOÁN BỆNH VIÊM RUộT MẠN TÍNH
}

\section{TÓM TẮT}

Đặt vấn đề: Viêm ruột mạn tính (IBD) là bệnh lý có cơ chế bênh sinh phức tap và đang có xu hướng tăng lên trên thế giới. Chẩn đoán cần có sự phối hợp đăc điểm lâm sàng, kết quả nội soi và hình thái mô bệnh học $(\mathrm{MBH})$ đặc biệt trong những trường hợp không điển hình. Nghiên cứunày được thực hiện với mục tiêu khảo sát độ phù hợp trong chẩn đoán IBD giữa kết quả $\mathrm{MBH}$ và hình ảnh nội soi. Phương pháp nghiên cứu: Nghiên cứu hồi cứu mô tả được thực hiện tại Bệnh viện Đại Học Y Hà Nội từ tháng 2/202010/2020trên bệnh nhân có kết quả nội soi theo dõi viêm loét đai trực tràng chảy máu (VLĐTTCM) hoặc Crohn và đối chiếu với kết quả $\mathrm{MBH}$. Các tiêu bản sau đó được đọc độc lập lần 2 bởi chuyên gia giải phẫu bênh về IBD, sau đó đối chiếu lai với kết quả lần 1 và hình ảnh nội soi. Kết quả nghiên cứu: Có 46 bệnh nhân thỏa mãn tiêu chuẩn lựa chọn, tuổi trung bình 44,23(14,5), min max 19-74, tỷ lệ nữ/nam là 1,3.Trên nội soi, $89,1 \%$ các bệnh nhân được chẩn đoán là VLĐTTCM, chỉ có 5 bệnh nhân là Crohn (10,9\%). Mức độ đồng thuân giữa kết quả nội soi và $\mathrm{MBH}$ lần 1 và lần 2 ở mức thấp và trung bình với hệ số $\mathrm{k}$ tương ứng là 0,265 và 0,491 . Mức đô đồng thuân của kết quả $\mathrm{MBH} 2$ lần ở mức trung bình $(\mathrm{k}=0,487)$. Kết luận: Nghiên cứu ghi nhận mức độ đồng thuận giữa kết quả nội soi và $\mathrm{MBH}$ cũng như giữa hai lần chẩn đoán $\mathrm{MBH}$ có ý kiến của chuyên gia đều ở mức thấp và trung bình $(\kappa<0,6)$.

Tư khoá: viêm ruột mạn tính, mô bệnh học, kết quả nội soi.

\section{SUMMARY \\ EVALUATION OF AGREEMENT BETWEEN ENDOSCOPIC AND HISTOPATHOLOGY RESULTS FOR THE DIAGNOSIS OF INFLAMMATORY BOWEL DISEASE}

\footnotetext{
${ }^{1}$ Trường Đại học Y Hà Nôi

Bênh viên Đại hoc Y Hà Nôi

${ }^{3}$ Viện nghiên cúu và đào tạo Tiêu hoá, gan mạt

${ }^{4}$ Trướng Đai hoc Y dước, Đại hoc Quốc gia Hà Nội

Chịu trách nhiệm chính: Đào Việt Hằng

Email: daoviethang@hmu.edu.vn

Ngày nhận bài: 14.12.2020

Ngày phản biên khoa hoc: 25.01.2021

Ngày duyệt bài: 10.2.2021
}

\section{Đào Việt Hằng ${ }^{1,2,3}$, Vũ Việt Sơn ${ }^{2}$, Trần Thị Thu Trang ${ }^{3,4}$, Đào Thị Luận ${ }^{1,2}$}

Introduction: Inflammatory bowel disease (IBD) is a disease with complicating pathophysiology and increasing prevalence worldwide. Diagnosis of IBD, especially in atypical cases, is based on the combination of clinical symptoms, endoscopic and histopathology results. Our study aimed to evaluate the level of agreement on the diagnosis of IBD between endoscopic and histopathology results. Methods: a descriptive retrospective study was conducted at Hanoi Medical University Hospital from February 2020 to October 2020 in patients who had endoscopy images suspected of ulcerative colistis (UC) or Crohn's diseases and had histopathology reports. The biopsy samples were examined independently by a histopathologist specialized in IBD in second round; the expert's reports were compared with the first reports and the endoscopic results. Results: 46 patients met the selection criteria, the mean age was 44.23 (14.5), min-max was $19-74$, the female/male ratio was 1.3 . On endoscopy, $89.1 \%$ of patients were diagnosed with UC, only 5 patients were diagnosed with Crohn's disease (10.9\%). The levels of agreement between the endoscopy results and the first and the second histopathology reports were poor and moderate with $\mathrm{k}$ coefficients of 0.265 and 0.491 , respectively. The level of aggrement between the first and the second histopatholoy reports was moderate ( $\mathrm{K}$ $=0.487$ ). Conclusion: The levels of aggrement between endoscopic results and histopathology results with and without expert opinion were low and medium $(\mathrm{\kappa}<0.6)$.

Keyword: Inflammatory bowel disease, IBD, histopathology, endoscopy.

\section{I. ĐăT VẤN ĐỀ}

Bênh viêm ruôt man tính (Inflammatory Bowel Disease - IBD) được đặc trưng bởi tình trạng viêm mạn tính của niêm mạc ruột với cơ chể bênh sinh khá phức tap trong đó có vai trò củamột số yễu tố đã được xác định như nhiễm khuẩn, yếu tố di truyền, di ứng và cơ chế tự miê̂n[1]. Theo một nghiên cứu phân tích gộp công bố năm 2017 dựa trên 147 nghiên cứu về IBD, tỷ lệ mắc bênh cao nhất được báo cáo ở Châu Âu và Bắc Mỹ. Từ năm 1990, tỷ lê mắc IBD đang tăng lên ở cả những nước đang phát triển, trong đó có châu Á[2]. Tuy nhiên có những vùng 
như khu vực Đông Nam Á, trong đó có Việt Nam dữ liệu về dịch tễ học còn hạn chế.

Trong IBD, viêm loét dại trực tràng chảy máu (VLĐTTCM) vàCrohn là hai thể bệnh chínhcần được xác địnhđể giúp lựa chọn chiến lược điều trị phù hợp. Tuy nhiên, trong nhiều trường hợp, đặc điểm lâm sàng, hình ảnh nội soi và mố bệnh hơ $(\mathrm{MBH})$ có thể không điển hình và dễ nhầm lẫn với nhiều bệnh lý khác khiến việc chẩn đoán phân biệt gặp nhiều khó khăn[3]. Cho đến nay, Hội Crohn và viêm đại tràng châu Âu (ECCO) và Hiệp hội X-quang Tiêu hoá và bụng Châu Âu [ESGAR] trong khuyến cáo năm 2018 cũng khẳng định không thật sự có tiêu chuẩn vàng trong chẩn đoán và phân loại IBD mà phải dựa vào sư kết hợp của triệu chứng lâm sàng, đặc điểm trên nội soi và $M B H[4]$. Các yếu tố ảnh hưởng đến kết quả $\mathrm{MBH}$ bao gồm số mảnh sinh thiết, vị trí sinh thiết, kinh nghiệm của nhà giải phẫu bệnh và sự phối hợp với dữ liệu lâm sàng[5].

Vì vậy, để có cơ sở cho việc đề xuất các biện pháp nhằm cải thiện tỷ lệ chẩn đoán xác định và phân loại thể bệnh IBD chính xác, chúng tôi thực hiện nghiên cứu này với mục tiêu: Khảo sát độ phù hợp trong chẩn đoán IBD giữa kết quả MBH và đặc điểm nội soi tại Bệnh viện Đại học Y Hà Nội.

\section{II. ĐỐI TƯợNG VÀ PHƯƠNG PHÁP NGHIÊN CỨU}

Thiết kế nghiên cứu: Hồi cứu mô tả.

Địa điểm và thời gian nghiên cứu:

- Địa điểm: Trung tâm Nội soi, Khoa Giải phẫu bệnh - Bệnh viện Đại Học Y Hà Nội.

- Thời gian: Từ tháng $2 / 2020$ đến tháng $10 / 2020$

\section{Đối tượng nghiên cứu}

\section{Tiêu chuẩn lựa chọn:}

- Được nội soi đại tràng toàn bộ hoặc nội soi đại tràng sigmacó hình ảnh nội soi nghĩ đến Crohn hoặc VLDTTCM và được sinh thiết;

- Các tiêu bản được lưu giữ để hội chẩn MBH độc lập lần 2.

Tiêu chuẩn loại trừ:

- Có sinh thiết polyp hoặc tổn thương nghi ngờ ung thu'/loạn sản kèm theo.

- Có xuất huyết tiêu hóa nhiều nên không đánh giá được đặc điểm bề mặt niêm mạc trên hình ảnh nội soi.

- Đại tràng chuẩn bị bẩn.

Quy trình đánh giá trên hình ảnh nội soi và MBH:

Đánh giá tổn thương trên nôi soi: Các đặc điểm tổn thương trên nội soi để nghĩ đến IBD bao gồm: sự biến mất của các mạng lưới vi mạch bình thường ở niêm mạc; niêm mạc phù nề, xung huyết; niêm mạc mỏng dễ chảy máu do chạm đèn soi hoặc tự rỉ máu (VLĐTTCM); có thể có các ổ loét áp tơ hay ổ loét đơn độc hoặc nhiều vị trí với các hình thái khác nhau (loét dọc, loét sâu, loét dạng sao); polyp giả viêm; niểm mạc có nhiều nốt viêm nổi gờ như hình ảnh lát sỏi; có thể có hẹp đường tiêu hóa (Crohn)[6]. Vị trí tổn thương được đánh giá dựa trên phân loại Montreal $[7,8]$.

Đặc điểm mô bệnh học: Bệnh nhân được lấy mẫu sinh thiết và gửi về khoa Giải Phẫu Bệnh, bệnh viện Đại Học Y Hà Nội. Kết quả MBH được ghi nhận hồi cứu. Tiêu bản sau đó được mượn lại để 2 bác sĩ giải phẫu bệnh đã có kinh nghiệm về $\mathrm{IBD}$ đoc lai độc lâp. Các mẫu $\mathrm{MBH}$ đầu tiên được đánh giá có tình trạng viêm niêm mạc mạn tính hay không. Nếu có, các tiêu bản sẽ được tiếp tục phân loại thành: không có đặc điểm của IBD hoặc nghĩ nhiều đến IBD hơn các nguyên nhân khác. Các trường hợp nghĩ đến IBD sẽ được tiếp tục phân tích, đánh giá để phân loại phù hợp với VLĐTTCM hoặc bệnh Crohn[9]. Đặc điểm MBH của hai bệnh lý này cụ thể như sau:

- VLĐTTCM: tổn thương liên tục ở lớp niêm mạc và dưới niêm mạc, tăng thâm nhập bạch cầu đơn nhân ở gần phía màng đáy lớp biểu mô, xâm nhập nhiều bạch cầu đa nhân trung tính hay gặp hình ảnh vi áp xe khe tuyến, giảm hoặc mất tế bào hình đài chếnhày, các khe tuyến méo mó, chia nhánh, teo, có thể hình thành u hat liên quan đến các khe tuyến bị phá hủy và các ổ loét.

- Crohn: tổn thương viêm xuyên sâu qua các lớp của thành ống tiêu hóa, tổn thương viêm "ngắt quãng" với các vùng tổn thương viêm khu trú xung quanh là những vùng niêm mạc lành trên mảnh sinh thiết, biến đổi cấu trúc khe, hình thành u hạt không liên quan đến tổn thương khe tuyến, xâm nhập nhiều tế bào lympho ở lớp biểu mô.

Xử lý và phân tích số liệu: Các số liệu được nhập và xử lý theo phần mềm thống kê $y$ học SPSS. Các biến định tính được biểu diễn dưới dạng tỷ lệ phần trăm, các biến định lượng được biểu diễn dưới dạng trung bình SD. Sử dụng hệ số kappa để đánh giá mức độ đồng thuận giữa các kết quả nội soi và kết quả mô bệnh học, và giữa các bác sĩ giải phẫu bệnh. Trong đó, cụ thể các mức độ đồng thuận như sau: $\kappa<0,4$ : yễu, 0,44-0,6: trung bình, 0,6-0,8: tốt, $0,8-1$ : rất tốt.

\section{KẾT QUẢ NGHIÊN CỨU}

Đặc điểm chung: Từ tháng 2/2020 đến tháng 10/2020, nghiên cứu thu tuyển 46 bệnh 
nhân thoả mãn. Đặc điểm chung của bênh nhân được trình bày tại bảng 2 . Trên hình ảnh nội soi, $89,1 \%$ các bệnh nhân được chẩn đoán là VLĐTTCM, có 5 bệnh nhân là Crohn $(10,9 \%)$. Tất cả bệnh nhân đều có niêm mạc phù nề và xung huyết, $92,7 \%$ các bệnh nhân có hình ảnh mất mạng lưới mạch máu.

Bảng 1. Đặc điểm chung của bệnh nhân trong mẫu nghiên cứu ( $n=46)$

\begin{tabular}{|c|c|}
\hline Đặc điểm & Kết quả * \\
\hline Tuổi, min-max & $\begin{array}{c}44,23(14,5) \\
19-74\end{array}$ \\
\hline Giới tính (nữ/nam) & $1,3(26 / 20)$ \\
\hline \multicolumn{2}{|c|}{ Đặc điểm nội soi } \\
\hline $\begin{array}{c}\text { Loại nội soi } \\
\text { Nội soi đại tràng sigma } \\
\text { Nôi soi đai tràng toàn bô }\end{array}$ & $\begin{array}{l}12(26,1) \\
34(73,9)\end{array}$ \\
\hline $\begin{array}{c}\text { Phân loại IBD trên nội soi } \\
\text { VLĐTTCM } \\
\text { Crohn }\end{array}$ & $\begin{array}{c}41(89,1) \\
5(10,9)\end{array}$ \\
\hline \multicolumn{2}{|c|}{ Đặc điểm bệnh nhân VLĐTTCM $(n=41)$} \\
\hline Phân loại tổn thương & \\
\hline Niêm mạc phù nề & $41(100)$ \\
\hline
\end{tabular}

\begin{tabular}{|c|c|}
\hline Niêm mạc xung huyết & $41(100)$ \\
\hline $\begin{array}{c}\text { Mất hình ảnh mạng lưới } \\
\text { mạch máu }\end{array}$ & $38(92,7)$ \\
\hline Có trợt & $36(87,8)$ \\
\hline Có lóét & $6(14,6)$ \\
\hline Niêm mạc dê̂́ chảy máu & $2(4,9)$ \\
\hline Phân loại Montreal & \\
\hline E1 & $18(43,9)$ \\
\hline E2 & $9(22,0)$ \\
\hline E3 & $10(24,4)$ \\
\hline Không đánh giá được & $4(9,7)$ \\
\hline
\end{tabular}

*Biểu diến dưới dạng n(\%) hoặc trung bình (SD)

Mức độ đồng thuận giữa kết quả nội soi và mô bệnh họckhi chẩn đoán IBD. Kểt quả $\mathrm{MBH}$ sẽ được đọc 2 lần bởi 2 bác sĩ giải phẫu bênh độc lập, trong đó bác sĩ lần 2 là bác sĩ có kinh nghiệm trong chẩn đoán IBD. Kết quả mức độ đồng thuận chẩn đoán IBD giữa kết quả nội soi và $\mathrm{MBH}$ được trình bày trong bảng 3 , bảng 4 . Mức độ đồng thuận giữa kết quả nội soi và $\mathrm{MBH}$ lần 1 , giữa kết quả nội soi và $\mathrm{MBH}$ lần 2 ở mức thấp và trung bình với hệ số $\mathrm{K}$ tương ứng là 0,265 và 0,491 .

Bảng 2. Sự phù hợp giữa kêt quả nội soi và mô bệnh học lân1 khi chẩn đoán IBD

\begin{tabular}{|c|c|c|c|c|c|c|}
\hline & \multicolumn{3}{|c|}{ Kết quả mô bệnh học lân 1} & \multirow[b]{2}{*}{ Tống } & \multirow[b]{2}{*}{$\mathbf{K}$} \\
\hline & & $\begin{array}{l}\text { Phù hợp với } \\
\text { VLĐTTCM }\end{array}$ & $\begin{array}{c}\text { Phù hợp với } \\
\text { Crohn }\end{array}$ & $\begin{array}{l}\text { Phù hợp với } \\
\text { viêm mạn tính }\end{array}$ & & \\
\hline \multirow{3}{*}{$\begin{array}{c}\text { Chấn đoán } \\
\text { nội soi }\end{array}$} & TD VLĐTTCM & 22 & 0 & 19 & 41 & \multirow{3}{*}{0,265} \\
\hline & \multirow{2}{*}{ ống } & 0 & 5 & 0 & 5 & \\
\hline & & 22 & 5 & 20 & 46 & \\
\hline
\end{tabular}

Bảng 3. Mức độ đồng thuận giữa kêt quả nội soi và mô bệnh học lân 2 khi chẩn đoán IBD

\begin{tabular}{|c|c|c|c|c|c|c|}
\hline & \multicolumn{3}{|c|}{ Kết quả mô bệnh học lần 2} & \multirow[b]{2}{*}{ Tổng } & \multirow[b]{2}{*}{$\mathbf{K}$} \\
\hline & & $\begin{array}{c}\text { Phù hợp với } \\
\text { VLĐTTCM }\end{array}$ & $\begin{array}{l}\text { Phù hợp } \\
\text { với Crohn }\end{array}$ & $\begin{array}{c}\text { Phù hợp với } \\
\text { viêm mạn tính }\end{array}$ & & \\
\hline \multirow{2}{*}{$\begin{array}{c}\text { Chẩn đoán } \\
\text { nội soi }\end{array}$} & TD VLĐTTCM & 33 & 3 & 5 & 41 & \multirow{3}{*}{0,491} \\
\hline & TD Crohn & 0 & 5 & 0 & 5 & \\
\hline \multicolumn{2}{|c|}{ Tống } & 33 & 8 & 5 & 46 & \\
\hline
\end{tabular}

Hệ số kgiữa kết quả mô bệnh học lần 1 và lần 2 được thể hiện tại bảng 5 . Mức độ đồng thuận giữa bác sĩ có kinh nghiệm và không có kinh nghiệm ở mức trung bình $(\kappa=0,487)$.

Bảng 4. Sự phù hợp giữa 2 lần đọc kêt quả mô bệnh học

\begin{tabular}{|c|c|c|c|c|c|c|}
\hline & \multicolumn{3}{|c|}{ Mô bệnh học lấn 2} & \multirow[b]{2}{*}{ Tổng } & \multirow[b]{2}{*}{$\mathbf{K}$} \\
\hline & & $\begin{array}{l}\text { Phù hợp với } \\
\text { VLĐTTCM }\end{array}$ & $\begin{array}{l}\text { Phù hợp } \\
\text { với Crohn }\end{array}$ & $\begin{array}{l}\text { Phù hợp với } \\
\text { viêm man tính }\end{array}$ & & \\
\hline \multirow{4}{*}{$\begin{array}{l}\text { Mô bệnh } \\
\text { học lần } 1\end{array}$} & TD VLĐTTCM & 22 & 0 & 0 & 22 & \multirow{4}{*}{0,487} \\
\hline & TD Crohn & 0 & 5 & 0 & 4 & \\
\hline & Viêm mạn tính & 11 & 3 & 5 & 20 & \\
\hline & Tống & 33 & 8 & 5 & 46 & \\
\hline
\end{tabular}

Nghiên cứu ghi nhận 5 trường hợp có kết quả mô bệnh học nghĩ nhiều đến viêm mạn tính. Tất cả các bệnh nhân này đều được nội soi đại tràng toàn bộ và lấy sinh thiết ở niêm mạc vùng tổn thương tối thiểu là 2 mảnh tuy nhiên kết quả ghi nhận không thây hình ảnh viêm đặc hiệu của IBD và cấu trúc các tuyến rõ.

\section{BÀN LUÂ̂N}

Nghiên cứu khảo sát mức độ đồng thuận giữa kết quả nội soi và MBHtrong chẩn đoán xác định và phân loại thể IBD.Trong nghiên cứu này, theo 
kết quả nội soi, tỷ lệ bệnh nhân được chẩn đoán VLĐTTCM cao hơn so với Crohn. Kểt quả này có sự tương đồng với các nghiên cứu dịch tễ trên thế giới báo cáo tỷ lệ mắc cao hớn đối với VLĐTTCM[10]. Trên thực tế, bệnh Cronh cũng gặp khó khăn hơn khi chẩn đoán do cần phân biệt với lao, đặc biệt đối với các nước đang phát triển như Việt Nam. Có $26,1 \%$ các bệnh nhân chỉ được nội soi trực tràng.Tỷ lệ chẩn đoán chính xác IBD so với tiêu chuẩn tham chiếu (cả VLĐTTCM và Crohn) đã được báo cáo đều được cải thiện đáng kể khi áp dụng nội soi đại tràng toàn bộ. Bởi vậy, theo khuyến cáo của một số Hiệp hội, nội soi đại tràng toàn bộ có vào hồi tràng (ileocolonoscopy) kết hợp với sinh thiếtcần được thực hiện thay vì nội soi trực tràng $[5,6]$. Tuy nhiển trong điều kiện như nước ta, sự quá tải về số lương bênh nhẩn tai các đơn vị nội soi dẫn đến tình trang nhiều người bệnh không thể đợi theo hẹn để thực hiện nội soi đại tràng toàn bộ được. Đây có thể là một lí do ảnh hưởng đến kết quả $\mathrm{MBH}$, đặc biệt đối với những trường hợp IBD không điển hình do không đánh giá được đầy đủ đặc điểm tổn thương của toàn bộ niêm mạc đại tràng.

Nghiên cứu ghi nhận mức độ đồng thuận chẩn đoán giữa kết quả nội soi và kết quả $\mathrm{MBH}$ lần 1 và lần 2 ở mức thấp và trung bình với hệ số $\kappa$ lần lượt là 0,265 và 0,491 . Điêu này cho thấy có sự khác biệt trong chẩn đoán giữa các nhà giải phẫu bệnh và nhà nội soi. Theo hướng dẫn của hội tiêu hóa Anh và đồng thuận Châu Âu, các mảnh sinh thiết nội soi nên được lấy cả từ vùng niêm mạc lành và bất thường cũng như đảm bảo số lượng tối thiểu 2 mảnh sinh thiết trên mỗi đoạn đại tràng hoặc tại vị trí tổn thương. Các mảnh sinh thiết cần được đựng trong các lọ bệnh phẩm riêng biệt với nhãn ghi vị trí lấy mẫu tương ứng $[5,6]$. Tuy nhiên, tại các nước đang phát triển như Việt Nam, còn nhiều khó khăn trong việc lấy mẫu sinh thiết như chưa có quy trình chuẩn hóa vị trí và số lượng mảnh sinh thiết tại các đơn vị y tế, chi phí nếu lấy cả niêm mạc vùng lành và nhiều mẫu tại các đoạn đại tràng. Bởi vậy, nhu cầu cần có sự đồng thuận trong hướng dẫn quy trình nội soi sinh thiết vừa phù hợp với tình hình thực tế của các cơ sở y tế vừa tối ưu hoá được chẩn đoán IBD là cần thiết.

Mức độ phù hợp thấp giữa chẩn đoán nội soi và $\mathrm{MBH}$ lần 1 , trung bình giữa chẩn đoán nội soi và $\mathrm{MBH}$ lần 2 cũng như giữa 2 kết quả $\mathrm{MBH}$ tương tự như kết quả trong một số nghiên cứu khác trên thế giới. Bentley và cộng sự đãbáo cáo độ chính xác trong chẩn đoán IBD dựa vào kết quả $\mathrm{MBH}$ dao động từ 60-64\% đối với Crohn và $74 \%$ đối với VLE்TTCM, khả năng chẩn đoán và tái lập cũng ở mức trung bình hoặc kém đối với tất cả cácchẩn đoán phân loại IBD đối với cả nhóm chuyên gia và không chuyên gia $(\kappa<0,6)$. Tuy nhiên, việc sử dụng nhiều mảnhsinh thiết đã cải thiên khả năng chẩn đoán và tái lậpchẩn đoánso với sinh thiết qua trực tràng với chỉ số $\mathrm{K}$ cho VLĐTTCM là 0,64 và 0,53 , bệnh Crohn là 0,43 và 0,38 tương ứng với nhóm chuyên gia và không chuyên gia. Do đó, để tăng độ chính xác của kết quả $\mathrm{MBH}$ cần phối hợp các dữ liệu lâm sàng (tuổi, thời gian tiến triển bệnh, thời gian/phương thức điều trị, bệnh kèm theo, tiên sử du lịch) và hình ảnh nội soi [5]. Việc sử dụng các thang điểm $\mathrm{MBH}$ với tiêu chí đánh giá chi tiết có thể giúp các bác sĩ giải phẫu bệnh không có kinh nghiệm cải thiện kết quả chẩn đoán của mình và không có sự khác biệt giữa nhóm chuyên gia và không chuyên gia trong nhận định $\mathrm{MBH}$ nếu sử dụng cùng một tiêu chí dựa trên bằng chứng được thống nhất. Do đó, cồng tác đào tạo đối với các bác sĩ giải phẫu bệnh và sự phối hợp chặt chẽ với các bác sĩ lâm sàng, nội soi trong tiếp cận bệnh lý IBD đóng vai trò quan trọng.

\section{KẾT LUẦN}

Nghiên cứu ghi nhận mức độ đồng thuận giữa kết quả nội soi và $\mathrm{MBH}$ cũng như giữa hai lần chẩn đoán $\mathrm{MBH}$ có ý kiến của chuyên gia đều ở mức thấp và trung bình $(\kappa<0,6)$. Trong tương lai, cần xây dựng những hướng dẫn cụ thể về quy trình nội soi sinh thiết, tăng cường hoạt động đào tạo nhằm tối ưu hoá khả năng tiếp cận chẩn đoán IBD phù hợp với từng cơ sở điêuu trị.

\section{TÀI LIÊU THAM KHẢO}

1. Actis, G.C., et al., History of Inflammatory Bowel Diseases. J Clin Med, 2019. 8(11).

2. Ng, S.C., et al., Worldwide incidence and prevalence of inflammatory bowel disease in the 21st century: a systematic review of populationbased studies. Lancet, 2018. 390(10114): p. 2769-2778.

3. Flynn, S. and S. Eisenstein, Inflammatory Bowel Disease Presentation and Diagnosis. Surg Clin North Am, 2019. 99(6): p. 1051-1062.

4. Maaser, $\mathbf{C}_{\text {., }}$ et al., ECCO-ESGAR Guideline for Diagnostic Assessment in IBD Part 1: Initial diagnosis, monitoring of known IBD, detection of complications. Journal of Crohn's and Colitis, 2019. 13(2): p. 144-164K.

5. Magro, $F_{\text {., }}$ et al., European consensus on the histopathology of inflammatory bowel disease. J Crohns Colitis, 2013. 7(10): p. 827-51.

6. Annese, v., et al., European evidence based consensus for endoscopy in inflammatory bowel 
disease. J Crohns Colitis, 2013. 7(12): p. 982-1018.

7. Gajendran, M., et al., $A$ comprehensive review and update on Crohn's disease. Dis Mon, 2018. 64(2): p. 20-57.

8. Gajendran, M., et al., A comprehensive review and update on ulcerative colitis(). Dis Mon, 2019. 65(12): p. 100851.
9. Feakins, R.M. and G. British Society of Inflammatory bowel disease biopsies: updated British Society of Gastroenterology reporting guidelines. J Clin Pathol, 2013. 66(12): p. 1005-26.

10. M'Koma, A.E., Inflammatory bowel disease: an expanding global health problem. Clin Med Insights Gastroenterol, 2013. 6: p. 33-47.

\section{SO SÁNH MộT Số TÁC DUUNG KHÔNG MONG MUỐN CỦA PHƯƠNG PHÁP GÂY TÊ TỦY SỐNG - NGOÀI MÀNG CỨNG PHỐI HỢP VỚI GÂY TÊ TỦY SỐNG ĐƠ'N THUẦN ĐỂ MỔ LẤY THAI TRÊN SẢN PHỤ CÓ NGUY CƠ CAO TỤT HUYẾT ÁP}

\section{TÓM TẮT}

Mục tiêu: So sánh một số tác dung không mong muốn của phương pháp gẩy tê tủy sổng - ngoài màng cứng phối hợp với gây tê tủy sống đơn thuần để vô cảm cho mố lấy thai ở sản phụ có nguy cơ cao tụt huyết áp. Đối tượng, phương pháp nghiên cứu: Nghiên cứu tiến hành trên 60 sản phụ có chỉ định mổ lấy thai chủ động, có một trong các yếu tố nguy cơ cao tụt huyết áp sau gây tê tuỷ sông: đa thai, đa ối, thai to, được chia ngẫu nhiên thành hai nhóm để thực hiên 2 kỹ thuật vô cảm khác nhau: nhóm I gây tê tuỷ sống với liều bupivacaine theo chiều cao của bệnh nhân(cao <150cm: 7mg, từ 150 - 160cm: $8 \mathrm{mg}$, $>160 \mathrm{~cm}$ : $8,5 \mathrm{mg}$ ) và nhóm II gây tê tuỷ sống liều $5 \mathrm{mg}$ bupivacaine phối hợp với tê ngoài màng cứng $10 \mathrm{ml}$ Lidocaine $1 \%$ with adrenaline 1: 200000 , cả hai nhóm đều đước tiêm dưới nhên $30 \mathrm{mcg}$ fentanyl. Các thuốc co mạch sẽ được dùng điều chỉnh theo mạch, huyết áp của sản phụ. Các tác dung không mong muốn trên me và con được theo dõi liên tục trong 48 giờ sau mổ. Kết quả: Phương pháp gây tể tuỷ sống ngoài màng cứng phối hợp có tỷ lệ nôn, buồn nôn là $6,67 \%$ so với $23,3 \%$ ở nhóm gây tê tủy sống đơn thuân $(p<0,05)$. Tỷ lệ ngứa, rét run ở nhóm gây tê tuỷ sống - ngoài màng cứng phối hợp là $23,3 \%$ và $13,3 \%$ so với $26,6 \%$ và $26,6 \%$ ở nhóm gây tê tủy sống đơn thuần; không găp bênh nhân nào bi suy hô hấp, an thần sâu, đau đầu, bí tiểu ở cả hai nhóm. Điểm Apgar phút thứ nhất và phút thứ 5 của trẻ sơ sinh ở hai nhóm đều $>8$, không có sự khác biệt). Không gặp các biến chứng nguy hiểm trên mẹ và con. Kết luận: Phương pháp gây tê tuỷ sống - ngoài màng cứng phối hợp ít găp nôn, buồn nôn hơn so với phương pháp gây tể tủy sống đơn thuần. Các tác dụng không mong muốn khác trên mẹ và con không

\section{*Trường ĐHY Hà Nội}

**Bệnh viện Đa khoa Hồng Ngọc

Chịu trách nhiệm chính: Nguyên Đức Lam

Email: lamgmhs75@gmail.com

Ngày nhận bài: 14.12 .2020

Ngày phản biên khoa hoc: 25.01.2021

Ngày duyệt bài: 11.2.2021

\section{Nguyễn Đức Lam*, Nguyễn Thị Thu Ba**}

có sự khác biệt giữa hai nhóm. Không gặp các biến chứng nguy hiểm trên mẹ và con.

Tư khóa: Mổ lây thai, gây tê tuỷ sống, gây tê tuỷ sống - ngoài màng cứng phối hợp, tác dụng không mong muốn.

\section{SUMMARY \\ THE COMPARISON OF THE SIDE EFFECTS OF COMBINED SPINAL EPIDURAL ANESTHESIA VERSUS SPINAL ANESTHESIA FOR CESAREAN SECTION IN PREGNANT WOMEN WITH HIGH RISK OF HYPOTENSION}

Objective: To compare the side effects of combined spinal epidural anesthesia versus spinal anesthesia for cesarean section in pregnant women with high risk of hypotension. Methods: 60 pregnant women with high risk of hypotension (polyhydramnios, macrosomia or twins) underwent elective cesarean delivery were enrolled into this prospective, randomized, double-blind study. Patients were randomly divided into spinal anesthesia group (Group I) or combined spinal - epidural anaesthesia - CSE group (Group II). Group I received bupivacaine either $7 \mathrm{mg}, 8 \mathrm{mg}$ or $8,5 \mathrm{mg}$ bupivacaine depending on the heigh of patients $(<150 \mathrm{~cm}, 150-160 \mathrm{~cm},>160 \mathrm{~cm})$ with fentanyl 30mcg ; Group II received bupivacaine 5 $\mathrm{mg}$ with fentanyl $30 \mathrm{mcg}$ followed by epidural $1 \%$ lidocaine $10 \mathrm{~mL}$ with adrenaline 1:200 000 . The side effects were recorded during the surgery and 48 hours after surgery. Results: The rate of vomiting and nausea was $6.67 \%$ in CSE group and was $23.3 \%$ in the spinal anesthesia group ( $p<0.05)$. The rates of pruritus and chills in the group of combined spinalepidural anesthesia group were $23.3 \%$ and $13.3 \%$ compared with $26.6 \%$ and $26.6 \%$ in spinal anesthesia group. No patient suffered from respiratory distress, deep sedation, headache, and urinary retention in both groups. The infants' 1 st and 5th minute Apgar scores in both groups were $>8$, no significant difference). No dangerous complication of mothers and newborns was recognized. Conclusions: The rate of vomiting and nausea in CSE group was lower than in spinal anesthesia group, $p<0.05$. Other side 